\title{
Causal Perceptions of Intertrait Relations: The Glue That Holds Person Types Together
}

\author{
Constantine Sedikides \\ University of North Carolina at Chapel Hill \\ Craig A. \\ Anderson \\ University of \\ Missouri
}

Two experiments tested the hypothesis that implicit personality theory person types are composed of causally interconnected traits. Experiment 1 showed that the weakest trait member of a person type is perceived as more causally related to the core trait members of the type than are nonmember traits, even when those nonmember traits are both more highly correlated with and closer in multidimensional scaling (MDS) space to the core members than the weakest member. Experiment 2 demonstrated that within ${ }^{p}$ erson-type members are perceived as more causally related to each other than to members of other types even when all are located in the same MDS space. The hypothesis that person types consist of causally interrelated traits was strongly sup-ported. Implications for categorization, impression formation, and stereotyping are considered.

How do people think about the personalities of other people? In addressing this important question, psychologists have offered several theoretical accounts, three of which are particularly relevant to the present article: the associationistic view, the dimensional view, and the typological view.

According to the associationistic view, people think about others in terms of trait covariation. For example, if a person is perceived as honest, she or he will also be perceived as trustworthy, because these two traits are believed to covary. The simplest way to operationalize this view is through the Pearson product-moment correlation coefficient. According to the dimensional view, people think about others in terms of global dimensions (e.g., evaluation, dynamism) . This view is typically operationalized through factor analysis or multidimensional scaling (MDS). Traits located in the same multidimensional space are expected to co-occur. Finally, according to the typological view, people think about others in terms of person types. Person types are composed of several personality traits. Knowledge of a trait within a given person type can be used to predict the presence of other traits that belong to the same person type. The typological view is commonly operationalized through cluster-analytic procedures. Cluster analysis "correctly identifies cluster members both on the basis of how close they are to each other and on how far they are from other potential clusters" (Anderson \& Sedikides, 1991, p. 210) .

In a recent article, we articulated some implications of these three views and conducted a test of these implications (Anderson \& Sedikides, 1991, Experiment 1) . We first empirically derived associations, dimensions, and clusters on the basis of subjects' ratings of others' personalities. We subsequently demonstrated that the typological view offered insights regarding the nature of these representations that were not attained from the associationistic or dimensional view. Specifically, the typological view led to the identification of clusters of traits (i.e., person types) that were not clearly identified by either of the other two views. Most important, we showed that the person types had a form of structural interconnectedness that could not be accounted for by the associationistic or dimensional view.

In that earlier research, we operationalized person types as clusters. Each cluster had several trait members.

Authors' Note: We thank Norbert Schwarz and two anonymous reviewers for their very helpful suggestions on an earlier draft of this article. We also thank Jody C. Dill, Jennifer Stern, and Julliane Toppins for their assistance with data collection. Correspondence concerning this article should be addressed to Constantine Sedikides, Department of Psychology, University of North Carolina at Chapel Hill, CB \#3270, Davie Hall, Chapel Hill, NC 27599-3270

PSPB, Vol. 20 No. 3, June 1994 294-302

(c) 1994 by the Society for Personality and Social Psychology, Inc 
For each cluster, we identified the member with the lowest average intercorrelation with the other members (noncore and core members, respectively) . We also identified noncluster members (strong nonmembers) that had higher average intercorrelations with, and smaller MDS distances from, the core members than the non-core members had. We used this information in a subsequent experiment (Anderson \& Sedikides, 1991, Experiment 2) to demonstrate that, in comparison with strong nonmembers, noncore members were seen as a better fit with core members. That is, (a) noncore members were more likely than strong nonmembers to be spontaneously generated when subjects thought about another person who supposedly had the core members,

(b) noncore members were perceived as belonging to another person who supposedly had the core members to a greater extent than strong nonmembers were, and

(c) subjects estimated the probability of a person's having a noncore member, given that this person had the core member, as higher than the probability of having the strong nonmember.

To summarize, traits within a given person type appeared to have a powerful bond. This bond was stronger than simple associations between traits and stronger than spatial distances in multidimensional space. But what is the nature of this bond? What is it that keeps these traits together? What kind of relation are traits within a person type perceived to have? These are the questions that the present research addresses.

There are reasons to believe that traits in person types are causally interconnected. Causal thinking about others is pervasive. Perceivers form strong, resilient, and sometimes spontaneous causal links about person impressions and social events (Anderson, 1983; Anderson, New, \& Speer, 1985; Lalljee, Lamb, \& Abelson, 1992; Read, 1987; Uleman, 1987), comprehend stories through causal connections (Black, Galambos, \& Read, 1984; Hastie \& Pennington, 1991; Owens, Bower, \& Black, 1979; Pennington \& Hastie, 1992; Sedikides \& Anderson, 1992), reconstruct causal scenarios about events and social relationships (Harvey, Agostinelli, \& Weber, 1989; D. T. Miller, Turnbull, \& McFarland, 1989; L. C. Miller \& Read, 1991; Pennebaker, 1989; Taylor \& Schneider, 1989), and cognize their political world through causal scenarios (Axelrod, 1976; Conover \& Feldman, 1984; George, 1979). Thus it is plausible to expect that people perceive traits within person types to be, at least in part, interconnected through causal bonds. Take, for instance, the person type Depressed, which is composed of such core members as lonely, depressed, pessimistic, and unhappy (Anderson \& Sedikides, 1991). Perceivers may think that being lonely causes someone to be depressed, which, in turn, causes that person to be pessimistic and therefore unhappy. Alternatively, per- ceivers may think that being unhappy causes someone to be pessimistic and depressed, which, in turn, causes the person to be lonely. Stated otherwise, we expect most' causal connections of traits within person types to be bidirectional. The hypothesis that person types are composed of causally interconnected traits was evaluated by two experiments reported in this article.

\section{EXPERIMENT 1}

In Experiment 1, we asked subjects to rate pairs of traits for the extent to which one trait in the pair was likely to cause or underlie the other trait. The pairs were derived from the person types generated by Anderson and Sedikides (1991). We used 8 of the initial 11 person types. We excluded 3 person types (Sociable, Unsociable, and Egotistical) because they lacked strong nonmembers. Table 1 lists the person types we used, along with their core members, noncore members, and strong nonmembers.

For each person type, we derived all withincluster combinations of (a) core-noncore members and (b) core-strong nonmember traits. To evaluate the hypothesis that traits within a particular person type are causally related, we compared the mean causalness rating for core noncore pairs with the mean causalness rating for core-strong nonmember pairs. We did this for each cluster separately and for four different definitions of what qualified as a strong nonmember. According to the 0-D (zerodimensional-i.e., no consideration of MDS results) definition, all strong nonmembers had higher average intercorrelations with the core than the corresponding noncore member. According to the 2-D definition, strong nonmembers were both more highly correlated with the core members and closer in 2-D MDS space to the core members than the corresponding noncore members. The 3-D and 6-D definitions were used to ensure that our results were not artifacts of incomplete MDS solutions. That is, we wanted to know whether our findings would replicate when a more complete (i.e., a higher dimensionality) MDS solution was used.

For the hypothesis to be confirmed, the average causalness rating for core-noncore trait pairs should be significantly higher than the average causalness rating for core-strong nonmember trait pairs. Stated otherwise, for the hypothesis to be confirmed, noncore members should be more causally related to the core members than strong nonmembers, even though the strong non-members are (a) more highly correlated with the core members and (b) closer in MDS space to the core members. In essence, this procedure controls for causal perceptions arising from perceived covariations among traits and from dimensional similarity among traits. 
296 PERSONALITYAND SOCIAL PSYCHOLOGY BULLETIN

TABLE 1: Person Types (clusters) Used in Experiment 1

\begin{tabular}{|c|c|c|c|c|c|}
\hline $\begin{array}{l}\text { Person Type } \\
\text { (Cluster) }\end{array}$ & Members & $\begin{array}{c}\text { Strong } \\
\text { Nonmembers }\end{array}$ & $\begin{array}{c}\text { Person Type } \\
\text { (Cluster) }\end{array}$ & Members & $\begin{array}{c}\text { Strong } \\
\text { Nonmembers }\end{array}$ \\
\hline Extraverted & $\begin{array}{l}\text { Ambitious } \\
\text { Enthusiastic } \\
\text { Energetic } \\
\text { Outgoing } \\
\text { Confident }\end{array}$ & $\begin{array}{l}\text { Intelligent } \\
\text { Humorous } \\
\text { Friendly } \\
\text { Warm } \\
\text { Helpful } \\
\text { Pleasant }\end{array}$ & Untrustworthy & $\begin{array}{l}\text { Liar } \\
\text { Distrustful } \\
\text { Dishonest } \\
\text { Insincere } \\
\text { Unreliable }\end{array}$ & Unkind \\
\hline Intellectual & $\begin{array}{l}\text { Intelligent } \\
\text { Efficient } \\
\text { Competent } \\
\text { Studious }\end{array}$ & $\begin{array}{l}\text { Trustful } \\
\text { Honest } \\
\text { Reliable } \\
\text { Thoughtful } \\
\text { Helpful } \\
\text { Pleasant } \\
\text { Polite } \\
\text { Attentive }\end{array}$ & Spacey & $\begin{array}{l}\text { Forgetful } \\
\text { Indecisive } \\
\text { Gullible } \\
\text { Absentminded } \\
\text { Clumsy } \\
\text { Daydreamer }\end{array}$ & $\begin{array}{l}\text { Inconsistent } \\
\text { Careless } \\
\text { Lazy } \\
\text { Unreliable } \\
\text { Nosy }\end{array}$ \\
\hline Trustworthy & $\begin{array}{l}\text { Truthful } \\
\text { Honest } \\
\text { Trustful } \\
\text { Reliable } \\
\text { Dependable }\end{array}$ & $\begin{array}{l}\text { Thoughtful } \\
\text { Helpful }\end{array}$ & Aggressive & $\begin{array}{l}\text { Domineering } \\
\text { Aggressive } \\
\text { Dominating } \\
\text { Possessive }\end{array}$ & $\begin{array}{l}\text { Stubborn } \\
\text { Critical } \\
\text { Short-tempered } \\
\text { Overconfident } \\
\text { Boastful } \\
\text { Self-centered } \\
\text { Conceited }\end{array}$ \\
\hline Depressed & $\begin{array}{l}\text { Depressed } \\
\text { Lonely } \\
\text { Gloomy } \\
\text { Pessimistic }\end{array}$ & $\begin{array}{l}\text { Impolite } \\
\text { Boring }\end{array}$ & & & $\begin{array}{l}\text { Unkind } \\
\text { Angry }\end{array}$ \\
\hline & $\begin{array}{l}\text { Unhappy } \\
\text { Fearful }\end{array}$ & & Unsocialized & $\begin{array}{l}\text { Rebellious } \\
\text { Disobedient } \\
\text { Inconsistent } \\
\text { Careless } \\
\text { Lazy }\end{array}$ & $\begin{array}{l}\text { Liar } \\
\text { Unreliable } \\
\text { Impolite } \\
\text { Selfish } \\
\text { Dishonest } \\
\text { Unkind } \\
\text { Insincere }\end{array}$ \\
\hline
\end{tabular}

NOTE: The last trait listed under "Members" is a noncore trait. The remaining traits listed under "Members" are core traits.

\section{Method}

Subjects were 60 undergraduates participating for extra introductory psychology credit. Subjects were run in small groups of up to eight persons. Partitions set on the tables in the experimental room prevented subjects from seeing one another while seated.

Subjects received a booklet containing all stimulus materials. The first page of the booklet contained de-tailed instructions making the following points: (a) People frequently use personality traits to describe people.

(b) Some traits seem to cause or underlie other traits.

(c) Examples include insecure causing or underlying rude, easy-going causing or underlying uncomplaining, and sportsmanlike causing or underlying winner. (These example traits did not appear on subsequent pages of the booklet.) (d) The main task in the study is to decide how likely it is for one trait in a pair to cause or underlie the other. (e) This is to be done for a large number of trait pairs on the following pages. "how

likely it is for the first trait in the pair to cause or underlie the second trait") on a 9-point scale labeled as follows: 1 = extremely unlikely, 2 = very unlikely, $3=$ moderately unlikely, 4 = slightly unlikely, $5=$ neither unlikely nor likely, $6=$ slightly likely, $7=$ moderately likely, $8=$ very likely, $9=$ extremely likely.

Subjects were provided with the trait pairs in three random orders (Presentation Order) .
Further, the position of each trait in a given pair was set to first for half the subjects and to second for the other half (Causalness Order). These two factors were manipulated in a between-subjects fashion. The third factor in the experimental design was composed of the critical comparison (i.e., average causalness rating for core-noncore trait pairs vs. average causalness rating for core-strong nonmember trait pairs). This factor, Pair Type, was a repeated-measures factor. Thu, each subject rated 182 trait pairs, of which 32 involved core-noncore traits and 150 involved core-strong nonmember traits.

\section{Results and Discussion}

We performed separate analyses of variance (ANOVAs) for each cluster and for each of the four definitions of 
TABLE 2: Average Causalness Rating for Core -Noncore Member Pairs Versus Core -Strong Nonmember Pairs in Experiment 1: Zero-, Two-, Three-, and Six Dimensional Definitions of Strong Nonmember Traits

\begin{tabular}{lccccc}
\hline $\begin{array}{l}\text { Definition of Strong } \\
\text { Nonmember }\end{array}$ & $\begin{array}{c}\text { Mean Core- } \\
\text { Noncore Member } \\
\text { Causalness Rating }\end{array}$ & $\begin{array}{c}\text { Mean Core- } \\
\text { Strong Nonmember } \\
\text { Causalness Rating }\end{array}$ & Mean Difference & F(1, 54) of Difference & $\mathrm{p}$ \\
\hline 0-D & 6.28 & 5.60 & +.68 & 127.62 & .0001 \\
2-D & 6.52 & 5.86 & +.66 & 139.41 & .0001 \\
3-D & 6.49 & 5.85 & +.64 & 8.98 & .004 \\
6-D & 6.50 & 5.71 & +.79 & 64.20 & .0001 \\
\hline
\end{tabular}

Note: ratings could range from 1 to 9: higher numbers indicate greater perceived casualness.

strong nonmember. Preliminary analyses revealed no reliable effects of Presentation Order or Causalness Or-der. Hence, these factors are not discussed further.

Results across the various clusters were remarkably consistent and were therefore collapsed, as presented in Table 2. As can be seen, the mean causalness rating for the corenoncore trait pairs was significantly higher than the mean causalness rating for the core-strong nonmember trait pairs for all four definitions. These results con-firmed our hypothesis: Person types consist of causally linked traits.

\section{EXPERIMENT 2}

Experiment 1 showed that even a noncore member (i.e., the weakest member of a person type) is perceived as more causally related to the core members of that person type than are strong nonmembers (i.e., those traits that are more highly correlated with, and are closer in MDS space to, the core than the noncore members). Hence, the results of Experiment 1 suggest that at least part of the special bond among traits within a person type is a perception that the traits are causally related.

A second way of examining this same bonding question is to ask whether traits within a person type are generally perceived as more causally related to one an-other than to other traits that share the same MDS space. ${ }^{2}$ Figure 4 of Anderson and Sedikides (1991), reproduced in this article as Figure 1, presents the aver-age MDS location of the 11 identified person types. It reveals three sets of closely related clusters. One set contains the Unsocialized, Egotistical, Untrustworthy, and Unsociable clusters. A second set contains the Intellectual, Sociable, and Trustworthy clusters. A third set contains the Depressed and Spacey clusters. Experiment 2 focused on these three sets and tested our prediction that traits within a cluster will be seen as more causally related to one another than to traits sharing the same 2-D MDS space.

Figures 2, 3, and 4 present expanded 2-D plots of traits contained in the three sets listed above. As can be seen, the 2D plots do not cleanly separate the target person types.

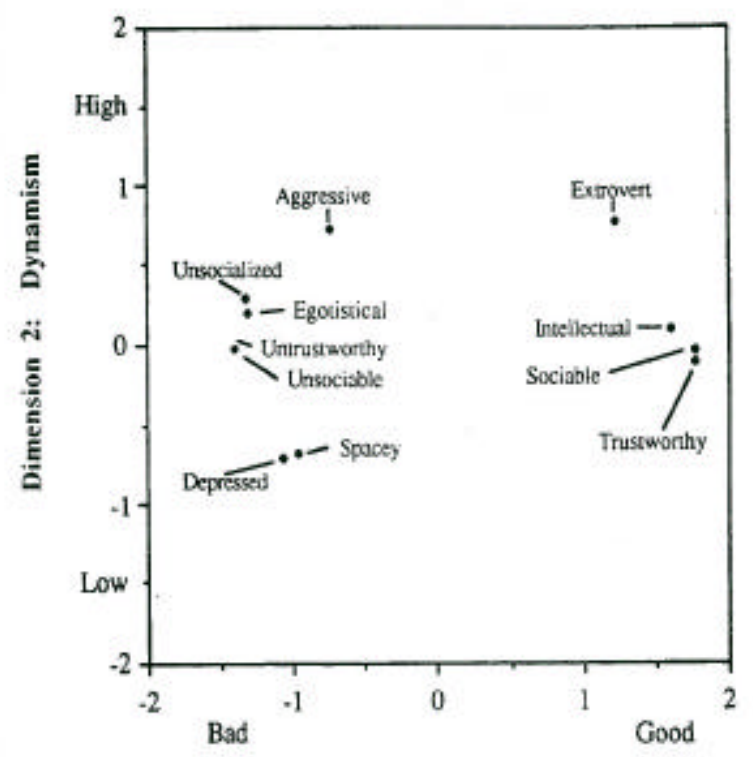

Dimension 1: Evaluation

Figure 1 Plot of clusters in two-dimensional multidimensional scaling space. From "Thinking About People: Contributions of a Typological Alternative to Associationistic and Dimensional Models of Person Perception" by C. A. Anderson and C. Sedikides,1991,Journal of Personality and SocialPsychology,

60, p. 209. Copyright 1991 by the American Psychological Method Association. Reprinted by permission.

Overview. For each of the three sets of person types sharing the same MDS space, subjects rated how causally related they perceived the various trait pairs to be. All possible pairs of traits within the relevant space were rated. Average within-type ratings (pairs of traits from the same person type) were compared with average between-type ratings (pairs of traits not from the same person type) . Subjects were randomly assigned to examine one of these three sets of traits. For each set, traits were listed across the top and down the left side of a matrix in alphabetical order. Subjects rated each pair of traits on this matrix. Half the subjects rated how likely the side traits were to cause or underlie the top traits; the 


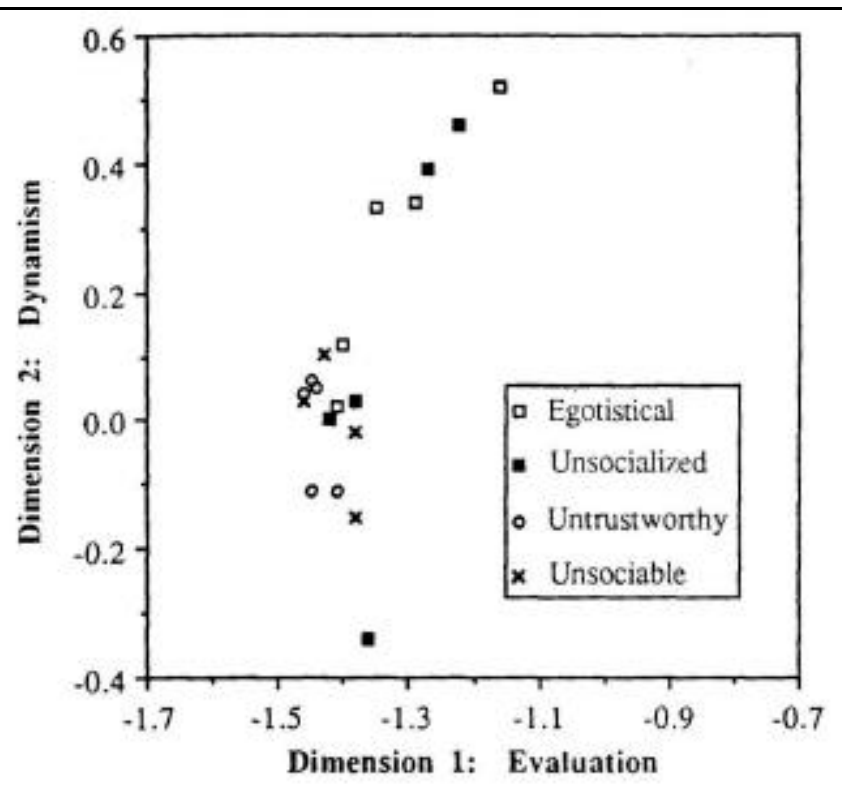

Figure 2 Plot of Set 1 traits in two-dimensional space.

other half rated how likely the top traits were to cause or underlie the side traits. Both male and female subjects participated. Because preliminary analyses yielded no consistent or interesting effects of gender or of top versus side rating direction, these between-subject variables will not be discussed further. The basic design is thus a simple two-level repeated-measures design, the two levels being average within-person-type versus average between-person-type ratings of causality. Data from each of these three sets of traits were analyzed separately to provide three independent replications of the experiment.

Stimuli. Three sets of traits were derived from the results of Anderson and Sedikides (1991). Set 1 included all the traits from the Unsocialized, Egotistical, Untrustworthy, and Unsociable person types. There were 19 traits in those clusters. Set 2 included the 16 traits from the Intellectual, Sociable, and Trustworthy person types. Set 3 included the 12 traits from the Depressed and Spacey person types. Table 3 shows the nine person types (or clusters) and 47 traits used.

Subjects and procedure. Ninety undergraduates participated for course credit, 30 in each of the three sets. Five to six subjects participated at a time, seated at desks with barriers between them to provide maximum privacy while completing the rating task.

Packets varying in trait set (Set 1, 2, or 3) and causal rating direction (top or side) were distributed randomly to subjects. The first page of each packet contained the same detailed instructions as in Experiment 1. In addition, a concrete example of how to use the trait matrix table in performing the rating task was given. Instruc-

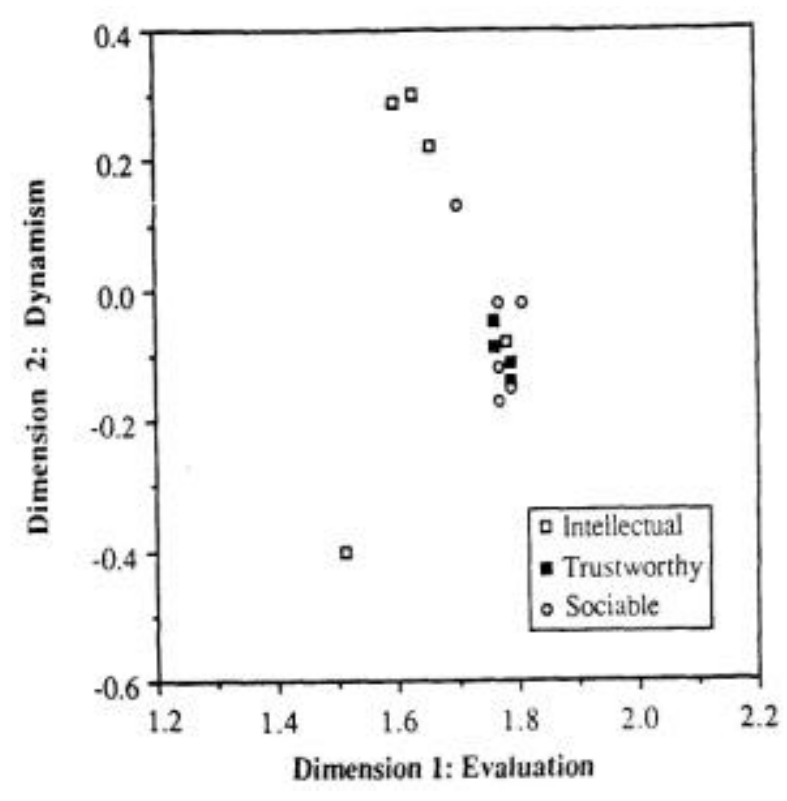

Figure 3 Plot of Set 2 traits in two-dimensional space.

tions on whether the ratings were to be based on the top traits as causes of the side traits or vice versa were provided. The same causalness rating scale as in Experiment 1 was used.

\section{Results and Discussion}

CAUSALNESS RATINGS WITHIN AND BETWEEN PERSON TYPES

We analyzed each set separately. For each subject, we calculated the average causalness rating for pairs of traits that came from the same person type (within-type average) and the average rating for all other trait pairs (between-type average). These two averages were analyzed in a repeated-measures ANOVA. If the bond that makes traits within a person type unique is perception of causal links among traits, then we should observe larger "within" averages than "between" averages.

Set 1: Unsocialized, Egotistical, Untrustworthy, and Unsociable Subjects did perceive within-type pairs of traits to be moderately to very causally related to each other, $M=7.34$. Traits from different person types were not seen as causally related even though they shared the same location in MDS space, $M=5.48$. As expected, this difference in perceptions was highly significant, $F(1,29)=326, p<.0001$ (Figure 5) .

Set 2: Trustworthy, Sociable, and Intellectual. Subjects again perceived within-type pairs of traits to be moderately to very causally related to each other, $M=7.32$. Similarly, the between-type pairs of traits were again seen as largely unrelated, $M=5.36$. As in Set 1 , this difference in perceptions was highly significant, $F(1,29)=211, p<.0001$ (Figure 5). 


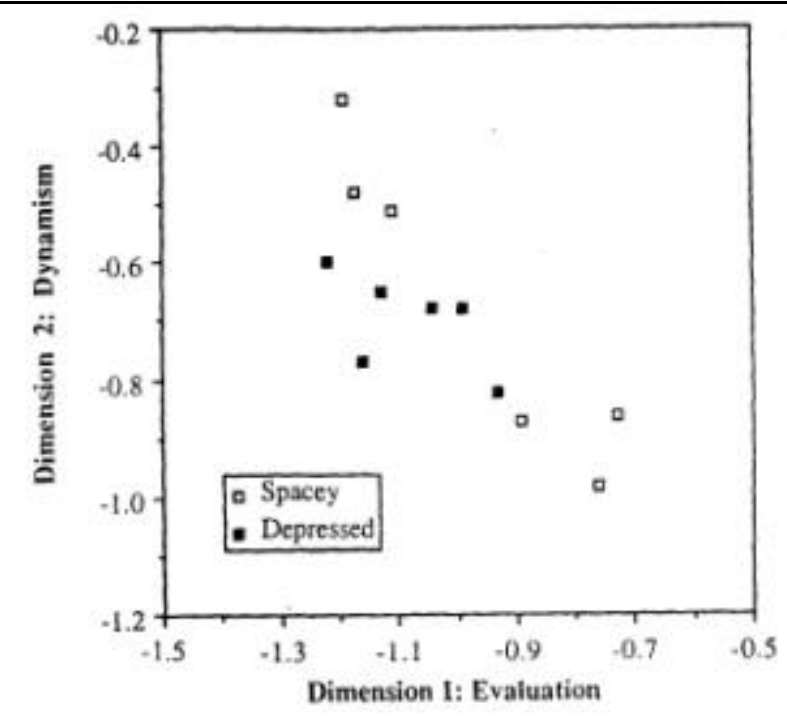

Figure 4 Plot of Set 3 traits in twodimensional space.

Set 3: Spacey and Depressed. Subjects perceived withintype pairs of traits to be moderately related to each other in a causal fashion, $M=6.85$. The between-type pairs of traits were perceived as causally unrelated, $M=4.73$. This difference in perceptions was highly significant once again, $\mathrm{F}(1,29)=181, \mathrm{p}<.0001$ (Figure 5).

CAUSALNESS VERSUS MULTIDIMENSIONAL

SCALING DISTANCES AND PERSON TYPES

A second set of analyses examined three related is sues: (a) Is the distance between a trait pair (as measured by the MDS analyses in Anderson \& Sedikides, 1991) systematically related to the perceived causal relatedness of the pair? (b) Does the distance between a trait pair predict whether the pair is awithin-person-type or betweenperson-type pair? (c) Does the perceived causalness of a trait pair predict whether the pair is a within- person-type or between-person-type pair even after any effects of distance are partialed out of the model?

Distance and causalness. For the restricted sets of traits under current investigation, we expected MDS distance to be weakly to moderately correlated with causalness in a negative direction. If the full set of 108 traits had been used, we would expect very strong negative correlations, because traits that are seen as causally related to each other (e.g., self-centered and selfish) tend to be attributed to the same person. This produces high cooccurrence scores in the type of person description task used in Anderson and Sedikides (1991), which, in turn, tend to produce small distances in MDS space. Conversely, pairs of traits that are conceptually or evaluatively opposite to each other (e.g., self-centered and thought- ful) are seen as causally unrelated (or inhibiting) to each other, are seldom attributed to the same person, and ought to yield large distances in MDS space. The three separate sets of person types examined in this study were selected for study because they fall in roughly the same MDS space. This should reduce the magnitude of the negative correlation between distance and causalness but is unlikely to eliminate it.

As expected, the 2-D MDS distance between a trait pair was significantly but modestly correlated with the average causalness rating of the pair in a negative direction. The correlations for Sets 1,2 , and 3, respectively, were- $-27(n=$ $171, p<.001), \quad-.42 \quad(n=120, \mathrm{p}<.001)$, and -.31 $(\mathrm{n}=66, \mathrm{p}<.02)$.

Distance and pair type. Previous analyses illustrated in Figure 5 showed that causalness ratings were strongly related to pair type. That is, pairs from the same person type had higher causalness scores than pairs containing traits from different person types. Is MDS distance also related to pair type? To address this question in the most direct way possible, we coded pair type as zero if the two traits were from a different person type and as one if from the same person type. Given that causalness and distance are correlated with each other and that causalness is theoretically important in determining whether a trait pair is perceived as being in the same person type, a negative correlation between distance and pair type might reasonably occur. However, the restricted range of trait pairs examined in each of the three sets is likely to minimize such correlations.

Not surprisingly, only one of the three correlations was significant. For Set 2 person types, greater distance between paired traits was associated with the pair coming from different person types, $r=-.29, p<.01$. The other two sets yielded nonsignificant correlations, ps $>.40$.

Causalness versus distance. Our view of the importance of causalness as a determinant of people's implicit personality theories predicts that partialing out the effects of MDS distance will not eliminate the causalness effect. That is, we expected that causalness ratings of trait pairs would be significantly and positively related to our pair type code, even after partialing out 2-D MDS distances. Regression analyses confirmed this prediction for each of the three sets of person types. The partial slopes for causalness were .16, .30, and .28 for Sets 1,2 , and 3 , respectively. The $F$ values for these parameters were all large $(>61$, all ps $<.0001)$.

CAUSALNESS RATINGS AND PERSON TYPES

A third type of analysis was performed to see how well causalness ratings could reproduce the person types derived by Anderson and Sedikides (1991). Recall that, in the original study, subjects rated targets on each of 108 
Used in Experiment 2

\begin{tabular}{ll}
\hline Person Type (Cluster) & \multicolumn{1}{c}{ Traits } \\
\hline Set 1 & Rebellious, disobedient, inconsistent, careless, lazy Selfish, conceited, self-centered, boastful, \\
Unsocialized & overconfident Liar, distrustful, dishonest, insincere, unreliable Cold, impolite, unfriendly, unkind \\
Egotistical & Intelligent, efficient, competent, studious \\
Untrustworthy & $\begin{array}{l}\text { Thoughtful, friendly, warm, helpful, pleasant, cooperative, polite Truthful, honest, trustful, reliable, } \\
\text { Unsociable }\end{array}$ \\
dependable & Depressed, lonely, gloomy, pessimistic, unhappy, fearful Forgetful, indecisive, gullible, absentminded, clumsy, \\
Intellectual & daydreamer \\
Sociable & \\
Trustworthy & \\
Set 3 & \\
Depressed & \\
Spacey &
\end{tabular}

traits. A co-occurrence similarity matrix of traits was created from these ratings. Cluster analyses of this matrix produced the derived person types.

In the present study, subjects merely rated the causal relation between trait pairs for selected person types, which were chosen for their similar location in MDS space in Anderson and Sedikides (1991) . Cluster analyses were performed on the distance matrixes (one for each set) derived from these causalness ratings. The causalness ratings were converted to distances by subtracting the average causalness rating of each pair from 10. The question of interest is: Do these causalness data tend to reproduce the person-type clusters originally derived in such a totally different person-rating task? If the glue that holds implicit personality theories together is perceived causalness of traits, then the clusters derived from these two totally different approaches should tend to look alike.

Set 1. We used the SAS CLUSTER procedure with an AVERAGE linkage rule. We also used the PSEUDO $F$ method to determine the optimal level of clustering.

Set 1 consisted of the four person types labeled Egotistical, Unsociable, Untrustworthy, and Unsocialized by Anderson and Sedikides (1991). The pseudo F statistic from the analysis of the present causalness distance matrix suggested that the optimal number of clusters for these traits was five, rather than four. Three of the five clusters were identical to those derived by Anderson and Sedikides: Egotistical, Unsociable, and Untrustworthy. The Unsocialized cluster was further broken down into two separate clusters consisting of the following traits: (a) careless, lazy, and inconsistent; (b) disobedient and rebellious. In other words, the causalness data reproduced to a surprising degree the person types originally derived from descriptions of real people.

Set 2. Set 2 consisted of the three person types labeled Intellectual, Sociable, and Trustworthy by Anderson and Sedikides (1991). The pseudo F on the present data suggested that three clusters was the optimal solution.

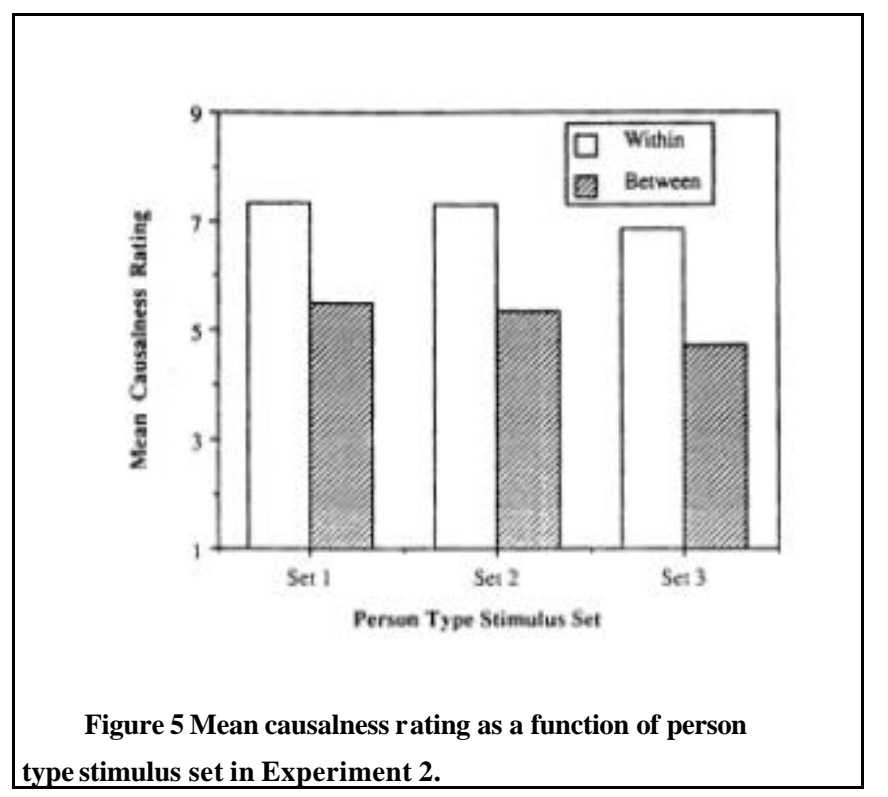

The three clusters derived from the causalness ratings were identical to the person-description-based person types.

Set 3. Set 3 consisted of the two person types labeled Depressed and Spacey by Anderson and Sedikides (1991) . The pseudo Fon the present data suggested that two clusters formed the optimal solution. The resulting two clusters were, once again, identical to the person types derived by Anderson and Sedikides (1991)

In sum, cluster analyses of trait causalness ratings produced the same person types as similar analyses on ratings of real people. The causal "glue" seems very strong indeed!

\section{GENERAL DISCUSSION}

We proposed that person types are composed of traits that are perceived as causally interrelated. Experiment 1 demonstrated that noncore members of person types are perceived as more causally related to the core members than are strong nonmembers that are both more highly 
correlated with and closer in MDS space to the core members. Experiment 2 showed that within-persontype members are perceived as more causally related to each other than to members of other types even when all are located in the same MDS space. We conclude that perceptions of causality play an important role in accounting for the bonding of traits within person types.

We do not, however, wish to argue that causal inter-connections are the only glue that holds withinpersontype trait pairs together. Such trait pairs may also be interconnected by other bonds, such as imaginability (i.e., within-type trait pairs may be easier to imagine together, possibly because of their comparable levels of concreteness or abstractness, than between-type trait pairs) or evaluation (i.e., within-type trait pairs may share a stronger evaluative bond, such as evaluative consistency, than betweentype trait pairs). Nevertheless, our results clearly allow us to conclude that causal interconnections form one rather strong bond between person-type traits.

Several other scholars have posited that people think about the personalities of other people in terms of person types rather than associations or dimensions (e.g., Andersen \& Klatzky, 1987; Bern \& Funder, 1978; Cantor \& Mischel, 1977; Forgas, 1983; Schneider \& Blankmeyer, 1983). In a similar vein, various scholars have shown that people think about other social groups, such as the elderly (Brewer, Dull, \& Lui, 1981), women (Deaux, Winton, Crowley, \& Lewis, 1985), or Blacks (Devine \& Baker, 1991), in terms of person types. The present research advances this work by elucidating an important aspect of the internal structure of person types-namely, the causal interconnections among their elements.

The obtained findings have implications for research on person memory, particularly for research examining memory for information that is consistent versus inconsistent with a prior impression (for a review, see Stangor \& McMillan, 1992). The present findings suggest a new definition of inconsistency: Inconsistent traits are traits that are not part of a given person type. Alternatively, inconsistent traits may be defined as those with negative causal connections.

The finding that social categories, such as person types, have a unique integrity or internal interconnectedness is compatible with the emerging view from re-search on concept and classification learning that categories are best understood by conceptualizing their elements in terms of interactive relations (e.g., Carey, 1982; Jacoby \& Brooks, 1984; Whittlesea, 1987). Our findings further promote this view by establishing one specific form of interactive relations: causal connections.

The obtained results also have implications for the way social groups are perceived. Person types can be broadly conceived as a form of stereotypes. From this perspective, our findings could partly explain why stereo-types are so resistant to change (Taylor, 1981): Traits ascribed to a particular group are glued together through causal connections, and causal connections or "theories" are notoriously resistant to change (e.g., Anderson \& Kellam, 1992; Anderson \& Sechler, 1986).

Conceptualizing person types as stereotypes leads to another interesting implication of our findings: their potential for deriving stereotypes with evaluatively opposite traits. Our original procedures (Anderson \& Sedikides, 1991) did not allow for this, because evaluatively opposite traits correlate negatively in the total population. However, the present results open up the possibility of identifying stereotypes containing evaluatively opposite traits by means of causalness ratings. Such stereotypes could be composed of a hierarchically arranged system of features, so that the superordinate feature (e.g., race, gender, occupation) can be rated as causally related to two subordinate traits that are them-selves usually seen as negatively related. For example, actors or actresses might be seen as being causally related to both Outgoing and Self-centered, even though these two traits will in general be seen as negatively related to each other.

This newly found causal link among trait elements in person types suggests several promising lines of theoretical and applied work. Work on belief perseverance and change has not merely shown that causal beliefs are unusually resistant to change; it has also shown that causal thinking can be used to reduce belief perseverance and to promote belief change (e.g., Anderson, 1982; Anderson \& Sechler, 1986; Koriat, Lichtenstein, \& Fischhoff, 1980; Lord, Lepper, \& Preston, 1984; Slusher \& Anderson, 1993). Slusher and Anderson (1993), for in-stance, demonstrated that a causally focused persuasive communication was more successful in changing erroneous beliefs about AIDS transmission than a comparable communication that did not focus on causal reasoning. The persuasive communication also significantly influenced people's level of commitment to work on AIDS-related issues. It would be useful to know whether similar success could be obtained in changing erroneous race- and gender-based stereotypic beliefs and consequent behaviors through persuasive communications focusing on causal thinking.

\section{NOTES}

1. For some person types, causal connections between traits are likely to be directional. This is especially true for extreme stereotypes. For instance, being Black may be seen as causing laziness, but being lazy is not seen as causing Blackness. Such laziness, but being lazy is not seen as causing Blackness. Such clear-cut examples do not appear in our stimuli, but weak examples are present. For instance, with the Intellectual efficient is to intelligent. And within the Depressed 
cluster, fearful may be more causally linked to unhappy than unhappy is to fearful. In the two experiments reported in this article, we control-led for directionality effects (by using two causalness orders) but did not test for them.

2. One way of highlighting just how complementary these two approaches are to each other is to note that a small portion of the between-type pairs in Experiment 2 involve a trait defined as a strong nonmember (in Experiment 1) and a core trait from that person type. Specifically, $10.2 \%$ of the between-type pairs were of this kind. Further, if one includes strong nonmember trait/noncore member pairs as well, the figure increases to $13.1 \%$.

\section{REFERENCES}

Andersen, S. M., \& Klatzky, R. L. (1987). Traits and social stereotypes: Levels of categorization in person perception. Journal of Personalityand Social Psychology, 53, 235-246.

Anderson, C.A. (1982). Inoculation and counterexplanation: Debiasing techniques in the perseverance of social theories. Social Cognition, 1, 126-139.

Anderson, C. A. (1983). The causal structure of situations: The genera-tion of plausible causal attributions as a function of type of event situation. Journal of Experimental Social Psychology, 19, 185-203.

Anderson, C. A., \& Kellam, K. L. (1992). Belief perseverance, biased assimilation, and covariation detection: The effects of hypothet ical social theories and new data. Personality and SocialPsychology Bulletin, 18, 555 565

Anderson, C. A., New, B.L., \& Speer, J. R. (1985) . Argument availability as a mediator of social theory perseverance. Social Cognition, 3, 235-249.

Anderson, C. A., \& Sechler, E. S. (1986). Effects of explanation and counterexplanation on the development and use of social theories. Journal of Personality and Social Psychology, 50, 24-34

Anderson, C. A., \& Sedikides, C. (1991). Thinking about people: Contributions of a typological alternative to associationistic and dimensional models of person perception. Journal of Personality and Social Psychology, 60, 203-217.

Axelrod, R. (1976). Structure of decision. Princeton, NJ: Princeton University Press.

Bern, D.J., \& Funder, D. C. (1978) . Predicting more of the people more of the time: Assessing the personality of situations. Psychological Review, 85, 485-501.

Black, J. B., Galambos, J. A., \& Read, S. J. (1984) Comprehending stories and social situations. In R. S. Wyer, Jr. \& T. K. Srull (Eds.), Handbook of social cognition (Vol. 3, pp. 45-86). Hillsdale, NJ: Lawrence Erlbaum.

Brewer, M. B., Dull, V., \& Lui, L. ((1981). Perceptions of the elderly: Stereotypes as prototypes. Journal of Personality and Social Psychology, 41, 656-670.

Cantor, N., \& Mischel, W. (1977). Traits as prototypes: Effects on recognition memory. Journal of Personality and Social Psychology, 35, 38-48.

Carey, S. (1982). Conceptual changes in childhood. Cambridge, MA: MIT Press.

Conover, P.J., \& Feldman, S. (1984). How people organize the political world. American Journal of Political Science, 25, 617-645.

Deaux, K., Winton, W., Crowley, M., \& Lewis, L. L. (1985). Levels of categorization and content of gender stereotypes. Social Cognition, 3, 145-167.

Devine, P. G., \& Baker, S. M. (1991). Measurement of racia stereotype subtyping. Personality and Social Psychology Bulletin, 17, 44-50

Forgas, J. P. (1983). The effects of prototypicality and cultural salience on perceptions of people. Journal of Research in Personality, 17, 153-173.

George, A. L. (1979). The causal nexus between cognitive beliefs and decision-making behavior: The "operational code" belief system. In
L. S. Falkowski (Ed.), Psychological models in international politics (pp. 95-125). Boulder, CO: Westview.

Harvey, J. H., Agostinelli, G., \& Weber, A. (1989). Account making and the formation of expectations about close relationships. Review of Personality and Social Psychology, 10, 39-62.

Hastie, R., \& Pennington, N. (1991). Cognitive and social processes in decision making. In L. Resnick; J. Levine, \& S. Teasley (Eds.), Perspectives on socially shared cognition (pp. 308-327) Washington, DC: American Psychological Association.

Jacoby, L. L., \& Brooks, L. R. (1984). Nnanalytic cognition memory, perception, and concept learning. In G. H. Bower (Ed.), The psychology of learning and motivation (Vol. 18, pp. 147). San Diego, CA: Academic Press.

Koriat, A., Lichtenstein, S., \& Fischhoff, B. (1980). Reasons for confidence. Journal of Experimental Psychology: Human Learning and Memory, 6, 107-118.

Lalljee, M., Lamb, R., \& Abelson, R. P. (1992). The role of even prototypes in categorization and explanation. In W. Stroebe \& M. Hewstone (Eds.), European review of social psychology (Vol. 3 , pp. 153-182). Chichester, England: Wiley.

Lord, C. G., Lepper, M. R., \& Preston, E. (1984). Considering the opposite: A corrective strategy for social judgment. Journal of Personality and Social Psychology, 47, 1231-1243.

Miller, D. T., Turnbull, W., \& McFarland, C. (1989). When a coincidence is suspicious: The role of mental simulation. Journal of Personality and Social Psychology, 57, 581-589.

Miller, L. C., \& Read, S. J. (1991). On the coherence of mental models of persons and relationships: A knowledge structure approach. In GJ.O. Fletcher \& F. Fincham (Eds.), Cognition in close relationships (pp. 69-99). Hillsdale, NJ: Lawrence Erlbaum.

Owens, J., Bower, G. H., \& Black, J. B. (1979). The "soap opera" effect in story recall. Memory and Cognition, 7, 185-191.

Pennebaker, J. W. (1989) . Opening up: The healing power of confiding in others. New York: William Morrow.

Pennington, N., \& Hastie, R. (1992). Explaining the evidence: Tests of the story model for juror decision making. Journal of Personality and Social Psychology, 62, 189-206.

Read, S. J. (1987). Constructing causal scenarios: A knowledge struc ture approach to causal reasoning. Journal of Personality and Social Psychology, 52, 288-302.

Schneider, D. J., \& Blankmeyer, B. L. (1983). Prototype salience and implicit personality theories. Journal of Personality and SocialPsychobgy, 44, 712-722.

Sedikides, C., \& Anderson, C. A. (1992). Causal explanations of defection: A knowledge structure approach. Personality and SocialPsychobgy Bulletin, 18, 420-429.

Slusher, M. P., \& Anderson, C. A. (1993). The importance of causal information in counteracting belief perseverance Changing beliefs about the transmission of AIDS. Manuscript submitted for publication.

Stangor, C., \& McMillan, D. (1992). Memory for expectancycongruent and expectancy-incongruent information: A review of the social and social developmental literatures. Psychological Bulletin, 111, 42-61.

Taylor, S. E. (1981). A categorization approach to stereotyping. In D. L. Hamilton (Ed.), Cognitive processes in stereotyping and intergroup behavior (pp. 83-114). Hillsdale, NJ: Lawrence Erlbaum.

Taylor, S. E., \& Schneider, S. K. (1989). Coping and the simulation of events. Social Cognition, Z 174-194.

Uleman, J. S. (1987). Consciousness and control: The case of spontaneous trait inferences. Personality and Social Psychology Bulletin, 13, 337-354.

Whittlesea, B.WA. (1987). Preservation of specific experiences in the representation of general knowledge. Journal ofExperimentalPsychobgy: Learning, Memory, and Cognition, 13, 3 17.

Received September 10, 1992

Revision received March 17

1993 Accepted March 18

1993 